\title{
Modality-Specific Noun-Verb Dissociations in L1 but No Effect in L2: Evidence from Bilingual Aphasia
}

\author{
Maria Kambanaros \\ Cyprus University of Technology \\ kambanaros@gmail.com
}

\section{Abstract}

The spoken and written productions of object and action names in two languages of a multilingual speaker with aphasia were compared. The results showed preserved written naming for action words in L1 (Greek) in light of severe difficulties with spoken action names, whereas for object names the opposite pattern was observed. For L2 (English), severe difficulties retrieving action and object names for spoken and written naming were found. The finding supports the widely accepted view that the cognitive processes used for spoken and written naming are relatively independent components that can be selectively impaired after brain injury. In the case of bilingual speakers, the cognitive processes can involve both languages.

\section{Introduction}

Not much is known about spoken and written breakdown processes, particularly for verbs and nouns, in bilingual speakers after brain impairment. In this study, the spoken and written naming abilities of a simultaneous trilingual fluent aphasic individual in two of his (three) languages, Greek and English, which differ markedly in morphological complexity, orthographic transparency, and alphabetic script on action and object retrieval at the single-word level are reported.

\section{Background}

\subsection{Verb-noun Dissociations in Aphasia}

A substantial number of studies have dealt with dissociations between nouns and verbs using confrontation naming tasks depicting pictures of actions and

\section{(cc) BY-NC-ND}


objects. A small number of studies have identified dissociations between action and object naming in bilingual speakers with aphasia (see Kambanaros, 2009, for a detailed review). Taken together with evidence of dissociations from monolingual speakers with aphasia, these findings suggest that words are organized in the brain according to semantic and grammatical categories.

A different though related issue for grammatical class dissociations in aphasia is modality specificity. Research shows that brain damage can selectively impair verb and noun processing in opposite ways at different levels of the lexical system. The most commonly reported pattern has been selective impairment for action or object spoken word naming. These impairments can result from damage to the speech production system at one or more levels: the conceptual level, semantic-syntactic level, including lemma retrieval, or the phonological level including lexeme retrieval and at the level of articulation (Levelt, 1989). In the case of patients with bilingual aphasia, the locus of impairment at one or more levels of processing may be greater for one language compared to another depending on factors such as age of acquisition, familiarity and language dominance and moreover the effects of grammatical class may be different in each language (see Kambanaros, 2009 and references within).

Reports of impairment to written picture naming of nouns and verbs in aphasia are less common but nevertheless quite revealing. Caramazza and colleagues investigated lexical access for action and object names in a number of monolingual English speakers with aphasia and compared performance with the same items on oral and written word production tasks. In some cases, written word performance contrasted remarkably with spoken production (Rapp \& Caramazza, 2002). For example, a selective deficit with verbs might be restricted to written word production in some patients and to speech production in others (Caramazza \& Hillis, 1991) and in the case of a modality effect, a selective deficit might be found for one grammatical class only, e.g. impaired production for nouns in speech only (Hillis \& Caramazza, 1995).

Most intriguingly, Rapp and Caramazza (2002) established that the same patient may have greater difficulty with verbs in spoken word production and with nouns in written word production. The results strengthen the suggestion that not only are grammatical categories distinctive in the language system, the lexical processing system consists of modality-specific input and output components that reflect these distinctions at least for monolingual speakers of English (Hillis \& Caramazza, 1995).

Although the properties of the English grammatical system are unique (as in all languages), these patterns of modality-specific grammatical processing raise a question of whether bilingual speakers with aphasia would show modality-specific grammatical processing in one or both of their languages. A three-way interaction between grammatical class, modality of production, and language status, i.e. between the first acquired (L1) and the second acquired (L2) language, would suggest that the lexical processing system is highly modular 
(Forster \& Jiang, 2001). Furthermore, the neural organization of verbs and nouns is suggested to be highly independent as evidenced by extant studies in aphasia and brain imaging (see Obler et al., 2007, and references within).

\subsection{Greek Versus English}

Modern Greek is a stem-based language, unlike English (word-based), with a more complex morphology than English (Ralli, 2003). Morphophonological word forms are inflected according to grammatical category, for instance skoup-izi 'he/ she sweeps' is a verb and 'skoup-a' 'broom' is a noun. Thus, nouns and verbs are differentiated by different suffixes and are also marked for person and gender. Each stem in Greek is bound and only projected at the phonological word level after the correct inflectional suffix is attached to the stem at morphological level. Furthermore, the Greek gender system distinguishes masculine, feminine, and neuter. Nouns inflect for gender at the morphological level. However, nouns are not only assigned gender on the basis of word meaning, but also on the basis of more general morphological rules. For instance, nouns ending with the nominative singular suffix -as (o papas 'the priest') and with the accusative singular-a (ton papa) are masculine, whereas nouns ending with the nominative singular -as (to kreas 'the meat']) and the accusative singular -as (to kreas) are neuter. Gender agreement is also marked in Greek throughout the whole noun phrase, including determiners and adjectives.

Information about the grammatical category and about morpho-syntactic features, such as person, tense, aspect and mood for verbs or gender and case for nouns, are prominent aspects in Greek as they must be accurately projected, marked and expressed during single word production. In this manner, grammatical information also plays a crucial role in the selection and retrieval of the appropriate phonological and/or orthographic representation or lexeme via language-specific processes during morpho-phonological encoding.

\section{Methodology}

\subsection{Participant}

AA is a 25-year-old right-handed male university student who sustained a left parieto-occipital lesion verified by neuroimaging (CT) as a result of cerebral hemorrhage on February 19, 2006, while sleeping. An angiography conducted on February 21, 2006, revealed an arteriovenous malformation (AVM), that is, an abnormal tangle of blood vessels in the brain. AA has a right hemi paresis 
involving the arm and leg. Although AA was right-handed before his stroke he now writes only with his left hand. AA was born in Athens, Greece and was raised as a simultaneous bilingual hearing and speaking Greek, English and Arabic from infancy. However, he had been schooled all his life in Greek, with many years of English language instruction throughout his schooling in Greece, but has received no formal education in Arabic. AA's mother is Greek, his father Palestinian, and the home language is English. He has two younger brothers. AA was asked to rate his abilities in his three languages prior and post stroke in response to a self-rating language scale (adapted from Li et al., 2006) using a seven point scale ( 7 =excellent, $6=$ very good, $5=$ good etc) in the following modalities: understanding; communicating/speaking; reading; writing. There was no significant difference between prior and post-stroke abilities. He was also required to quantify his current domain of use for each language. Family members verified his responses. The results are presented in Table 1.

Table 1.

AA's self-rated estimates of proficiency in his different languages across linguistic domains and of language use (percentage).

\begin{tabular}{|l|l|l|l|}
\hline \multicolumn{2}{|l|}{ L1 (Greek) } & L2 (English) & L3 (Arabic) \\
\hline \multicolumn{2}{|l|}{ Estimates of proficiency (on a scale from 1 to 7) } & 5 \\
\hline Understanding & 7 & 6 & 5 \\
\hline Speaking & 7 & 7 & - \\
\hline Reading & 7 & 5 & - \\
\hline Writing & 7 & 6 & 12.5 \\
\hline Language use background (percentage) & & - \\
\hline Home life & 75 & 12.5 & 12.5 \\
\hline Tertiary Education & 100 & - & - \\
\hline Socializing & 75 & 12.5 & 12.5 \\
\hline Reading & 75 & 25 & \\
\hline Television/Radio & 12.5 & 75 & \\
\hline
\end{tabular}

AA considers Greek to be his predominant language and English and Arabic second languages with a greater ability in English, since he is unable to read and write Arabic. Hence Greek was classified as L1 and English as L2. AA had no premorbid writing disorder and his vision and hearing are normal. He was in his third year of a 4-year undergraduate degree in Building Renovation and Restoration at the Technological Educational Institute Patras, Greece, and he reads and writes Greek on a daily basis. This course also has three English language modules, of graded difficulty (intermediate-high-terminology), which AA has successfully completed. 
On the basis of the language assessment using the Boston Diagnostic Aphasia Examination (BDAE), AA presented with anomic aphasia characterized by fluent, well-articulated speech but mild to moderate anomia (word-finding difficulties) in both Greek (L1) and English (L2). His results on the BDAE are presented in Table 2. His auditory comprehension across language tasks was within normal limits and he showed intact conceptual abilities in both languages.

Table 2.

AA's performance on the BDAE in Greek and English.

\begin{tabular}{|l|c|c|}
\hline & $\begin{array}{c}\text { Greek } \\
\text { (L1) }\end{array}$ & English (L2) \\
\hline BDAE subtests & & \\
Word discrimination & $72 / 72$ & $72 / 72$ \\
Body parts & $20 / 20$ & $20 / 20$ \\
Commands & $15 / 15$ & $15 / 15$ \\
Complex ideation & $10 / 12$ & $8 / 12$ \\
Responsive naming & $24 / 30$ & $0 / 30$ \\
Confrontation naming & $92 / 114$ & $78 / 114$ \\
Animal naming & 2 & 0 \\
& & \\
\hline
\end{tabular}

BDAE: English version: Goodglass, H., \& Kaplan, E. (1983); Greek version: Papathanasiou et al., (2008)

\subsection{Materials}

Subtests of the Greek Object and Action Test (GOAT; Kambanaros, 2003) were administered to assess spoken and written retrieval of object and action names. The GOAT contains 84 items: 42 action and 42 object coloured photographs measuring $10 \times 14 \mathrm{~cm}$ in size. Subtests were pilot tested on a group of twenty non-brain injured, Greek-English bilingual speakers aged between 55 and 75 years; the GOAT was originally designed to assess noun and verb retrieval in bilingual aphasic speakers of Greek and English. Only items named with 80\% accuracy or more were included in the test. None of the Greek words in the test were English cognate words. Object pictures were concrete inanimate nouns and included manipulated instruments used for activities of daily living such as garage tools, garden equipment, kitchen utensils, household items, office and personal implements and included no body parts. All verbs were monotransitive and pictured actions were restricted to past stereotypical roles, that is, a woman was shown performing household activities (e.g. sweeping), and a man was performing more manly duties (e.g. hammering). All action names corresponded to either an instrumental verb (where an instrument is part of the action e.g. sweeping) or to a non-instrumental verb (e.g. climbing). There were no significant differences between the mean word frequencies for nouns (mean 89.31 per million) and verbs (mean 69.95 per million) across all English 
(L2) subtests of the GOAT. For Greek, lemma frequencies for object and action names were calculated based on the printed word frequency count for Greek (see Hatzigeorgiou et al., 2000).

A Mann-Whitney Test revealed no significant difference between object and action lemmas $[z=-0.154, p=0.878]$. In addition, there was no significant difference in syllable length between object and action names $[z=-0.610, p=0.542]$. Furthermore, object and action names were measured for key psycholinguistic variables, including age of acquisition (AoA), imageability and picture complexity. A Mann-Whitney test revealed that object and action names were not significantly different on AoA [ $z=-1.168, p=0.243]$, but there was a significant difference in ratings for word imageability $[z=-2.978, p=0.003]$ and picture complexity $[z=-2.331, p=0.20]$ with higher ratings for object compared to action names.

Of the object names, 7 were stressed on the ultimate syllable, 30 on the penultimate, and 5 on the antepenultimate. The action names were first conjugation (or paroxytone) verbs that are by far the most numerous in Greek, and all (but one) were stressed on the penultimate syllable. The internal word structure of verbs in $L 1$ consisted of [root + affix] for simple forms and [root + affix + affix] for more complex ones. Nouns in L1 were not controlled for gender. Of the total nouns (42), 6 were masculine, 15 were female and 21 were neuter. All responses were recorded in writing and also on audiotape.

\subsection{Procedures}

For spoken naming AA was shown the GOAT photographs individually (42 actions and 42 objects) and was asked to name the object or action in the picture using one word either in Greek or English according to the language investigated at the time. Each language was tested at least one week apart and subtests were given in random order. For written naming tested 10 days later, AA was asked to write the name of the object or action in the picture using one word either in Greek or English. Each language was tested at least one week apart and subtests were given in random order.

\section{Results}

\subsection{Spoken Naming}

AA was able to name $36 / 84$ (42.8\%) pictures correctly in L1 (19/42 or $45.2 \%$ action names and $17 / 42$ or $40.5 \%$ object names), and $24 / 84$ (28.5\%) pictures correctly in L2 (12/42 or $28.5 \%$ action names and $12 / 42$ or $28.5 \%$ object names). A chi- 
square analysis revealed a significant difference in verbal naming performances between L1 and L2 ( $\left.x^{2}=21.429 ; p<.001\right)$, with AA showing a better overall performance in $L 1$ compared to $L 2$, for both action names ( $x^{2}=8.679 ; p=.003$ ) and object names $\left(x^{2}=27.429 ; p<.001\right)$. Nevertheless, oral naming performances for action and object names were severely impaired in both languages.

Furthermore, there were non-significant differences between $A A^{\prime}$ s action and object naming performances both in L1 and L2. Moreover, similar error types were observed in both languages for action but not for object names. Specifically, no responses or some equivalent thereof (e.g., "Don't know") were the most prominent error type for action names in $\mathrm{L} 1$ (13/23 or 56.5\%) and L2 (16/25 or $64 \%)$ followed by semantic errors, $7 / 23$ (30.4\%) in L1 and 6/25 $(24 \%)$ in L2. Object names in contrast produced the largest number of omissions in L2 (24/29 or $83 \%)$, while in L1 errors for object names were divided between semantic errors ( $8 / 25$ or $32 \%)$, no responses ( $7 / 25$ or $28 \%$ ), and code-switching responses $(5 / 25$ or $20 \%)$.

\subsection{Written Naming}

AA was able to correctly write the names of $62 / 84$ (73.8\%) pictures in L1 (34/42 or $81.0 \%$ action names and $28 / 42$ or $66.6 \%$ object names), and $16 / 84$ (19.0\%) correct picture names in L2 (8/42 or $19.0 \%$ action names and $8 / 42$ or $19.0 \%$ object names). A chi-square analysis revealed a significant difference in written naming performances between $L 1$ and $L 2\left(x^{2}=3.429 ; p<.001\right)$, with AA showing a better written performance in L1 compared to $L 2$, for both action names ( $x^{2}=$ 5.250; $p=.022)$ and object names $\left(x^{2}=42.857 ; p<.001\right)$. Furthermore, there was a significant difference in $A A^{\prime} s$ performance for written action names compared to written object names in L1 $\left(x^{2}=5.950 ; p<.001\right)$, with a significantly better performance for action words. There was a non-significant difference in written naming between action and object words in $L 2$.

Furthermore, error types differed between the two languages for action and object names. Given the poorer performance in L2, both word types produced the same error type for action and object words viz. mainly no written responses (omissions) to the picture presented. On the other hand, for Greek (L1) the predominant error type for written action and object naming was mainly letter substitutions when writing action (7/7) and object (13/14) words. All spelling errors for action and object names in Greek involved a phonological-orthographic substitution of a single vowel in either word initial (3/7) or word medial position (4/7) for action and word final (8/13), initial (3/13), and both initial and final positions in the same word (2/13), for object words. All incorrect written naming attempts for action and object pictures were phonologically plausible alternatives for Greek (L1). All responses with coded error types are presented in Table 3. 
Table 3.

$A A^{\prime}$ s responses in $\mathrm{L} 1$ for action and object words in spoken and written naming.

\begin{tabular}{|c|c|c|}
\hline Picture & Written naming & Spoken naming \\
\hline \multicolumn{3}{|l|}{ Action name } \\
\hline 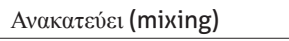 & + & NR \\
\hline 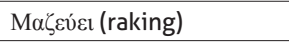 & + & NR \\
\hline 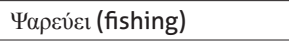 & + & NR \\
\hline$\Sigma \varepsilon \rho \beta i ́ \rho \varepsilon l$ (serving) & + & NR \\
\hline 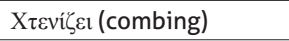 & + & NR \\
\hline 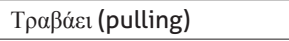 & + & NR \\
\hline$\Delta \dot{\varepsilon} v \varepsilon 1$ (tying) & + & NR \\
\hline Форá́ı (wearing) & + & NR \\
\hline Фо৩бкஸ́vยı (blowing) & + & NR \\
\hline 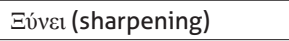 & + & NR \\
\hline 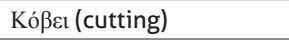 & + & 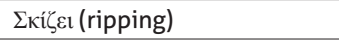 \\
\hline 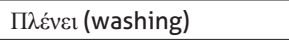 & + & 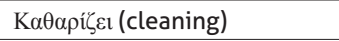 \\
\hline 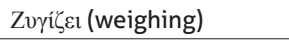 & + & 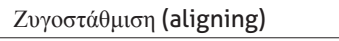 \\
\hline 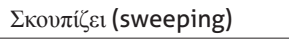 & + & 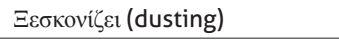 \\
\hline 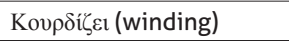 & + & A $\lambda \lambda \alpha \dot{\zeta} \zeta \varepsilon l$ (changing) \\
\hline$\Delta 1 \alpha \beta \alpha \dot{\alpha} \zeta \varepsilon 1$ (reading) & + & Koıtúsı (looking) \\
\hline 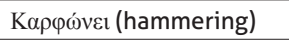 & + & $\Sigma \varphi v p i ́$ (hammer) \\
\hline 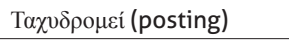 & NR & $\Delta \omega ́ \sigma \varepsilon \iota$ (giving) \\
\hline 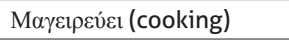 & 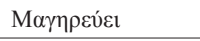 & + \\
\hline 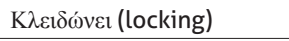 & $\mathrm{K} \lambda \varepsilon \imath \delta$ óvı & + \\
\hline 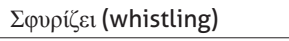 & $\Sigma$ фotpí̧̧є & + \\
\hline 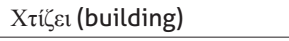 & 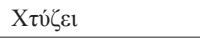 & DK \\
\hline$\Lambda \Perp \mu \alpha ́ \rho \varepsilon 1$ (filing) & $\Lambda v \mu \alpha ́ \rho \varepsilon \imath$ & DK \\
\hline$\Sigma 1 \delta \varepsilon \rho \omega ́ v \varepsilon ı$ (ironing) & $\Sigma 1 \delta \varepsilon \rho o ́ v \varepsilon 1$ & iron \\
\hline 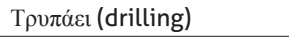 & 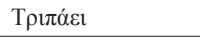 & 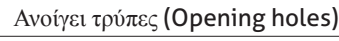 \\
\hline \multicolumn{3}{|l|}{ Object name } \\
\hline 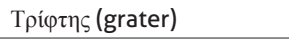 & + & 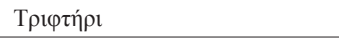 \\
\hline 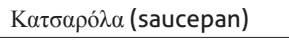 & + & Фoúpvos \\
\hline Пıvé̉o (paint brush) & + & 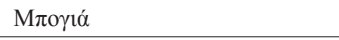 \\
\hline Bènóv $\alpha$ (needle) & + & 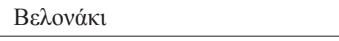 \\
\hline$\Sigma \kappa \alpha ́ \lambda \alpha$ (ladder) & + & 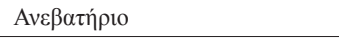 \\
\hline Mıкрópœvo (microphone) & + & 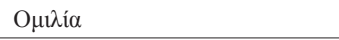 \\
\hline 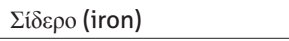 & + & iron \\
\hline 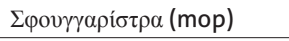 & + & mop \\
\hline 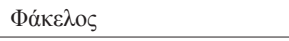 & + & envelope \\
\hline$\Sigma$ ¿vpí (hammer) & + & hammer \\
\hline Тбоvүкро́v $\alpha$ (rake) & + & NR \\
\hline$\Xi v ́ \sigma \tau \rho \alpha$ (sharpener) & + & NR \\
\hline Kó $\lambda \lambda \alpha$ (glue) & + & Ko $\lambda \lambda \alpha ́ \varepsilon 1$ \\
\hline
\end{tabular}


Table 3.

$A A^{\prime}$ s responses in L1 for action and object words in spoken and written naming.

\begin{tabular}{|c|c|c|}
\hline Picture & Written naming & Spoken naming \\
\hline 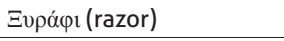 & + & $\Xi v \rho i ́ \zeta о \mu \alpha \imath$ \\
\hline$\Sigma \kappa о \cup ́ \pi \alpha$ (broom) & + & \\
\hline 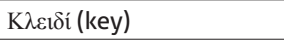 & $\mathrm{K} \lambda \varepsilon ı \delta \eta ́$ & + \\
\hline$\Sigma \varphi v \rho i ́ \chi \tau \rho \alpha$ (whistle) & $\Sigma \varphi \eta \rho i ́ \chi \tau \rho \alpha$ & + \\
\hline 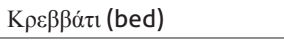 & 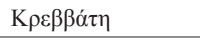 & + \\
\hline По $\lambda v \theta \rho o ́ v \alpha$ (couch) & 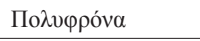 & + \\
\hline 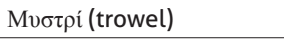 & $\mu \iota \tau \tau \eta \dot{~}$ & NR \\
\hline 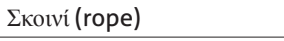 & бкоเvи́ & NR \\
\hline 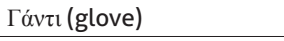 & 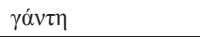 & NR \\
\hline 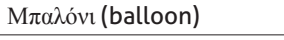 & $\mu \pi \alpha \lambda$ óv & NR \\
\hline$\Psi \alpha \lambda i ́ \delta 1$ (scissors) & $\psi \alpha \lambda i ́ \delta \eta$ & NR \\
\hline Kovoov́vı (bell) & 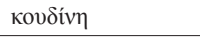 & $\mathrm{N} \tau \iota \nu-v \tau \iota v$ \\
\hline Av $\alpha \pi \tau \eta ́ \rho \alpha \varsigma$ (lighter) & $\alpha v \alpha \pi \tau \hat{\rho} \rho \alpha \varsigma$ & Tбıүó $\rho о$ \\
\hline 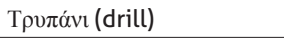 & $\tau \rho v \pi \alpha ́ v \eta$ & $\mu \pi \lambda \alpha \kappa \varepsilon v \tau \varepsilon \dot{\varepsilon} \kappa \varepsilon \rho$ \\
\hline Mo $\lambda \hat{\beta} \beta$ (pencil) & $\mu \mathrm{o} \lambda \dot{\beta} \beta \eta$ & pencil \\
\hline Потıбти́рı (watering can) & $\pi \circ \tau \imath \sigma \tau \eta ́ \rho \eta$ & 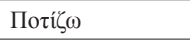 \\
\hline
\end{tabular}

Table 3 (a).

AA's responses in English (L2) for action and object words in spoken and written naming.

\begin{tabular}{|l|l|l|}
\hline Picture & Written naming & Spoken naming \\
\hline Action name & & \\
\hline stirring & + & NP \\
\hline cutting & NR & + \\
\hline reading & NR & watching \\
\hline singing & cinging & + \\
\hline tying & NR & NR \\
\hline weighing & NR & NR \\
\hline drawing & drowing & + \\
\hline ringing & NR & ticking \\
\hline combing & NR & NR \\
\hline sitting & siting & + \\
\hline building & blooing & NR \\
\hline sweeping & NR & NR \\
\hline watering & NR & NR \\
\hline sleeping & sleening & + \\
\hline pulling & NR & + \\
\hline serving & cerving & + \\
\hline drilling & NR & NR \\
\hline
\end{tabular}


Major Trends in Theoretical and Applied Linguistics

Table 3 (a).

AA's responses in English (L2) for action and object words in spoken and written naming.

\begin{tabular}{|c|c|c|}
\hline Picture & Written naming & Spoken naming \\
\hline painting & NR & brushing \\
\hline sewing & NR & NR \\
\hline lighting & NR & NR \\
\hline grating & NR & NR \\
\hline shaving & NR & NR \\
\hline glueing & NR & + \\
\hline sieving & NR & NR \\
\hline climbing & NR & + \\
\hline watching & wacing & + \\
\hline hammering & NR & NR \\
\hline raking & NR & gardening \\
\hline wearing & NR & dressing \\
\hline sharpening & NR & NR \\
\hline winding & NR & ticking \\
\hline locking & NR & closing \\
\hline whistling & bloei & NR \\
\hline filing & NR & NR \\
\hline \multicolumn{3}{|l|}{ Object names } \\
\hline spoon & NR & NR \\
\hline sponge & spang & Scotch brite \\
\hline (fishing) rod & NR & + \\
\hline tray & NR & serve \\
\hline scales & NR & NR \\
\hline comb & NR & + \\
\hline sieve & NR & NR \\
\hline tie & NR & + \\
\hline watch & wach & + \\
\hline newspaper & NR & NR \\
\hline file & NR & NR \\
\hline grater & NR & NR \\
\hline saucepan & NR & NR \\
\hline (paint) brush & NR & NR \\
\hline needle & NR & pin \\
\hline ladder & NR & + \\
\hline microphone & microfon & + \\
\hline mop & NR & NR \\
\hline envelope & NR & + \\
\hline hammer & hower & + \\
\hline rake & NR & gardening \\
\hline sharpener & NR & NR \\
\hline
\end{tabular}


Table 3 (a).

AA's responses in English (L2) for action and object words in spoken and written naming.

\begin{tabular}{|l|l|l|}
\hline Picture & Written naming & Spoken naming \\
\hline glue & + & + \\
\hline razor & NR & NR \\
\hline broom & brom & NR \\
\hline key & + & + \\
\hline whistle & NR & NR \\
\hline bed & NR & NR \\
\hline couch & koch & + \\
\hline trowel & NR & NR \\
\hline rope & NR & pull \\
\hline glove & NR & NR \\
\hline couch & koch & + \\
\hline trowel & NR & NR \\
\hline rope & NR & pull \\
\hline glove & NR & NR \\
\hline balloon & ballon & + \\
\hline scissors & scezer & + \\
\hline lighter & NR & NR \\
\hline drill & NR & NR \\
\hline (watering) can & + & NR \\
\hline
\end{tabular}

Key: + = Correct response. Written responses are organised according to error type. Corresponding spoken responses are classified as either correct, Omission (NR $=$ No response, Don't know responses or some equivalent thereof), Code switches (CSC=code switch correct), Semantic errors (single word or descriptions).

\section{Discussion}

AA exhibited a clear dissociation between (impaired) spoken naming and (relatively spared) written naming in his L1 (Greek) supporting the view that the grammatical categories of verbs and nouns are independent in the lexical processing system as argued by Caramazza and colleagues.

With regards to spoken picture naming we assume for AA, sustained damage at the level of the phonological output lexicon in L1 (Greek) and L2 (English) with his comprehension for action and object names in both languages preserved. AA was profoundly anomic on (single-word) picture naming tasks for both word categories across the two languages. This was confirmed by the large number of first, omission errors (e.g., "don't know" answers or no responses), and second, semantic errors, for both action and object names in L1 (Greek) and L2 (English). We assume that his spoken naming difficulties arose from a severe impairment 
of lexical-phonological representations or access to them. Semantic errors arose when the target word node was relatively unavailable and semantically related ones were activated and produced instead (Caramazza, 1997). This interpretation of a word retrieval deficit at the level of the lexical form is typical for aphasic patients diagnosed with anomia. Furthermore, he presented with no grammatical class dissociations in spoken (action/object) naming neither for L1 nor for L2. This finding is in tune with other studies in the (monolingual) aphasiology literature showing that fluent anomic aphasic individuals can suffer from undifferentiated grammatical word class dissociations on picture naming tasks (see Kambanaros, 2009, and references within).

However, the present finding is in contrast to previous studies of picture naming involving bilingual anomic aphasic speakers of Greek (L1) and English $(\mathrm{L} 2)$, that show dissociations between performance on lexical retrieval tasks with nouns and verbs in both languages (Kambanaros $\&$ van Steenbrugge, 2006). Selective impairment when accessing the phonological representations of familiar words due to damage at the level of the phonological output lexicon allow impaired oral production of the names of pictures, as in AA's case, but a spared ability in writing the name of the same pictures (see Hillis \& Caramazza, 1991, 1995, for a complete discussion). However, this was observed for AA only in L1 (Greek) for written picture naming of action and object words (albeit with a significantly higher performance for action words). This means that on the written picture-naming task AA was able to select an orthographic representation based on the corresponding phonological representation and input from the intact semantic system.

With regards to object names, the predominant written error was letter substitutions mainly orthographic errors, involving the grapheme [1] /i/ (iota) in word-final position being replaced by the grapheme [ $\eta$ ] (ita) /i/. The grapheme [1] (iota) is the most common noun ending for singular neuter nouns while [ $\eta$ ] (ita) is the most common noun ending for singular feminine nouns. AA's written error on (neuter) object words, in Greek, could be considered a morphological error in the sense that he assigned feminine gender to neuter nouns but we know this was not the case for two reasons: first, he retrieved the gender of every noun correct (100\%) either on the spoken naming task or when asked to provide noun gender by the examiner (author) on spoken nouns (GOAT), and second, he was able to write several other neuter nouns

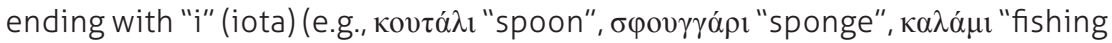
rod", poגó "watch", correctly. Furthermore all remaining errors for object words in Greek involved letter substitutions or orthographic replacements of graphemes representing the same vowel (e.g., ava túpas instead of

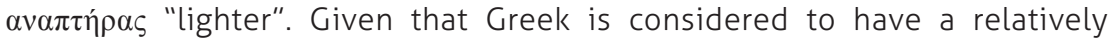
transparent orthography one possible explanation for his performance on written picture naming in Greek of neuter nouns is that he produced, via the 
non-lexical spelling or phonological route, used in transparent languages, written word-forms that were phonologically plausible alternatives, although incorrect in terms of word-specific orthography. There are several alternative spellings of the vowel " $i$ " (and other vowels) in Greek therefore wordspecific knowledge is required to write correctly any word containing (vowel) orthographic ambiguity even in Greek. Moreover, it is possible that access to the morphological rule for neuter noun declensions was partially available to AA (after stroke) and as such explains his mixed written picture naming performance mainly on (neuter) nouns.

In contrast, the most plausible account of AA's successful written naming of actions in Greek, is that it was not mediated by lexical-phonological knowledge but was instead facilitated by an independent pathway leading from the meaning of action words to their lexical-orthographic representations. It is possible that AA has developed some sort of visual orthographic memory that allows him to write correctly action words, including those containing phonemes that could be transcribed with more than one grapheme. All errors with written naming of action words involved phonological-orthographic substitutions of word-medial

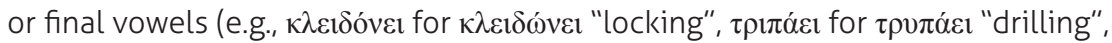
that were phonologically plausible alternatives.

\section{Conclusion}

AA presents with preserved written spelling for action words regardless of modality in Greek (L1). Notably, this contrasts with his severe difficulties with spoken picture naming of the same action words. AA's performance when naming objects across written naming tasks revealed a similar performance in $L 1$; he was significantly less impaired on writing object words compared to retrieving object names on a spoken naming task. In English (L2), AA showed similar performance across both tasks for action and object words, i.e. severe difficulties retrieving action and object names for spoken and written naming.

The unique finding in the present study is that this pattern of dissociation for action over object names was observed in L1 (Greek) but not in L2 (English). In L2 (English) there were similar levels of impairment across tasks (spoken and/ written naming) for both word types. This finding supports the widely accepted view that the cognitive processes which are used for naming and spelling tasks are relatively independent components that can be selectively impaired and/ or spared by brain impairment. In the case of bilingual speakers, the cognitive processes can involve both languages. However, the results show for the first time that language status ( $L 1$ versus L2) interacts with grammatical category and task in the patterns of acquired naming disorders manifest in bilingual speakers with aphasia. 


\section{References}

Caramazza, A. 1997. How many levels of processing are there in lexical access? Cognitive Neuropsychology 14, 177-208.

Caramazza, A. and Hillis, A. 1991. Lexical organization of nouns and verbs in the brain. Nature 349, 788-790.

Forster, K. and Jiang, N. 2001. The nature of the bilingual lexicon: Experiments with the masked priming paradigm. In J.N. Nicol (ed.), One Mind, Two Languages Bilingual Language Processing. Oxford: Blackwell Publishers, 72-83.

Goodglass, H. and Kaplan, E. 1983. The Assessment of Aphasia and Related Disorders ( $2^{\text {nd }}$ edition). Lea and Febiger: Philadelphia.

Hatzigeorgiou, N., Gavrilidou, M., Piperidis, S., Carayannis, G., Papakostopoulou, A. and Spiliotopoulou, A. 2000. Design and implementation of the online ILSP corpus. Proceedings of the Second International Conference of Language Resources and Evaluation (LREC), vol. 3, 1737-1740.

Hillis, A. and Caramazza, A. 1991. Category-specific naming and comprehension impairment: A double dissociation. Brain and Language 114, 2081-2094.

Hillis, A. and Caramazza, A. 1995. Representation of grammatical categories of words in the brain. Journal of Cognitive Neuroscience 7, 457-458.

Kambanaros, M. 2003. Verb and noun processing in late bilingual individuals with anomic aphasia. Doctoral dissertation, Flinders University, Adelaide.

Kambanaros, M. 2009. Grammatical word class distinctions in bilingual aphasia. In G. Ibanescu and S. Pescariu (eds.), Aphasia:Symptoms, Diagnosis, and Treatment. New York: Nova Science Publishers. 
Kambanaros, M. and van Steenbrugge, W. 2006. Noun and verb processing in Greek-English bilingual individuals with anomic aphasia and the effect of instrumentality and verb-noun name relation. Brain and Language 97, 162-177.

Levelt, W. 1989. Speaking. Cambridge, MA: MIT Press.

Li, P., Sepanski, S. and Zhao, X. 2006. Language history questionnaire: A webbased interface for bilingual research. Behavior Research Methods 38, 202-210.

Obler, K.L., Hyun, J.M., Conner, S.P., O'Connor, B. and Anema, I. 2007. Brain organization of language in bilinguals. In A. Ardila and E. Ramos (eds.), Speech and Language Disorders in Bilinguals. New York: Nova Science Publishers, 21-46.

Papathanasiou, I., Papadimitriou, D., Gavrilou, B. and Mihou, A. 2008. Psychometric data on the BDAE in a healthy adult population: the role of age and gender. Psychology 15, 398-410.

Ralli, A. 2003. Morphology in Greek linguistics: The state of the art. Journal of Greek Linguistics 4, 77-129.

Rapp, B. and Caramazza, A. 2002. Selective difficulties with spoken nouns and written verbs: A single case study. Journal of Neurolinguistics 15, 373-402. 
Major Trends in Theoretical and Applied Linguistics 